\title{
Award-winning paper in 2019
}

Papers published in Maritime Engineering are eligible for awards from the Institution of Civil Engineers. Papers from any of the ICE journals can be nominated for several awards. In addition, each journal has awards dedicated to their specific subject area.

On Thursday 4 June 2020, awards were announced for the following paper published in Maritime Engineering in 2019. The editorial panel nominated their best paper and an awards committee chaired by Tim Broyd allocated the awards

\section{David Hislop Award (also known as the Offshore award)}

The David Hislop Award was awarded to Jiang et al., (2019)

\section{Abstract}

Assessments of wave energy resources form the basis of plans for developing and using wave energy, and provide guidance about where to site wave power stations and how to design wave energy convertors. Various indexes, including the spatial and temporal distributions of wave energy fluxes, the occurrence of the effective significant wave height, monthly and seasonal variability and the frequency of high sea states, were calculated from the recent 37-year European Centre for Medium-Range Weather Forecasts ERA-Interim reanalysis of wave field data. The results showed that areas with abundant and stable exploitable wave energy in the South China Sea were mainly between the Luzon Strait and the southeast of the Indo-China Peninsula, where the annual average wave energy fluxes ranged from 10 to $18 \mathrm{~kW} / \mathrm{m}$ and the monthly and seasonal variability indexes were less than $2 \cdot 2$ and $1 \cdot 6$, respectively. The wave energy was found to be poor in some coastal areas of the Beibu Gulf, the Gulf of Thailand and the Sulu Sea. In the areas where wave energy was abundant, high sea states occurred frequently, meaning that it was relatively difficult to use the energy. Therefore, the wave energy resources and the frequency of high sea states need to be considered when choosing sites for wave energy farms.

\section{Halcrow Prize}

The Halcrow Prize was awarded to Hames et al., (2019)

\section{Abstract}

This paper outlines the evolution of joint probability methods in the design and assessment of sea defence structures in the UK, together with the key drivers for these different methods. It highlights why and how the joint exceedance curve techniques were developed initially from the late 1980s and early 1990s, as well as the reasons for the later development of the Join-Sea software system in the mid-1990s, as well as more recently, the implementation of more robust multivariate statistical approaches. The differences between these techniques are outlined, as well as potential errors accounting for how these different techniques are applied to assess different sea defence response functions.

\section{REFERENCES}

Jiang Bo, Guowei Wu, Jie Ding, Changlei Ma, Yizhou Fang and Xiaoyng Wang (2019) Assessment of the wave energy resource in the South China Sea. Maritime Engineering 172(1): 23-33, https://doi.org/10.1680/jmaen.2018.29.

Hames DP, Gouldby Ben P and Hawkes Peter J (2019) Evolution of joint probability methods in coastal engineering practice in the UK. Maritime Engineering 172(2): 45-54, https://doi.org/ 10.1680/jmaen.2019.4. 